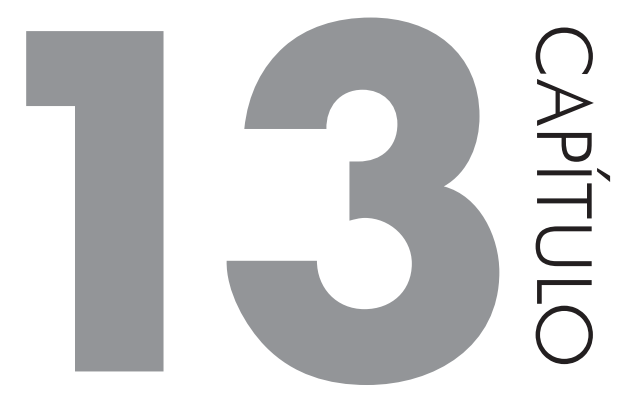

\title{
PANORAMA DE ASPECTOS SOCIOLINGUÍSTICOS DO ALTEAMENTO NO VOCALISMO POSTÔNICO MEDIAL EM PORTUGUÊS
}

ALESSANDRA DE PAULA ${ }^{1}$

\section{INTRODUÇÃO}

Este trabalho apresenta um breve panorama sociolinguístico do processo de alteamento das vogais médias /e/ e /o/ que tem gerado variação e mudança no vocalismo postônico medial do Português. Esse tema, que exige uma minuciosa investigação do léxico proparoxítono, tem sido pouco estudado até hoje, mas, desde um projeto de Iniciação Científica, em 2006, despertou o empenho investigativo das pesquisadoras Silvia Brandão e Alessandra de Paula. Desde então, sob a orientação de Brandão, De Paula empreendeu um estudo do fenômeno que resultou em sua dissertação de Mestrado e sua tese de Doutorado (DE PAULA, 2010; 2015), as quais estão aqui resumidas, além de diversos trabalhos (BRANDÃO; SANTOS, 2009; DE PAULA, 2008, 2014; DE PAULA; BRANDÃO, 2012, 2015; e outros). A

1 Silvia esteve presente em toda minha formação acadêmica e não sei me lembrar quando nossa parceria se tornou inseparável de nossas vidas, pois a amizade e o carinho que sinto por ela já são atemporais, emanam em tudo o que sou hoje e guiam os incontáveis caminhos que ainda iremos trilhar juntas. A ela agradeço pelo exemplo de excelência em tudo e pela profunda dedicação para que eu realizasse o melhor como professora e pesquisadora. 
pesquisa foi desenvolvida segundo os princípios teórico-metodológicos da Teoria da Variação e Mudança (LABOV, 1972, 1994; WEINREICH; LABOV; HERZOG, 2006), nas variedades de fala culta e popular do estado do Rio de Janeiro, além de ter tido seus aspectos comparados com o Português europeu e alguns estudos já realizados no Brasil, sob diferentes perspectivas teóricas.

É consabido na literatura que, desde a implementação do Português no Brasil, a redução das vogais em contextos átonos é um aspecto que tem traçado percursos de mudança fonológica muito diversos no Português brasileiro e no Português europeu (doravante PB e PE). A pesquisa de Brandão e De Paula chegou a resultados que são fundamentais para a compreensão do atual estágio dessas mudanças. Ela responde a questões sobre o vocalismo que surgiram na primeira abordagem fonológica sobre o Português, realizada por Joaquim Mattoso Camara Jr. (1953, 1977), especialmente no que diz respeito à sílaba postônica não final - um dos pontos da descrição de Mattoso Camara que acarretaram mais debates entre os teóricos que o sucederam.

Esse contexto diz respeito à penúltima sílaba das proparoxítonas, como nas palavras abóbora e pêssego, por exemplo, na qual o alteamento leva à instabilidade entre as vogais $[\mathrm{e}] \sim[\mathrm{i}] /[\mathrm{o}] \sim[\mathrm{u}]$. Esta pesquisa agregou novas informações ao debate sobre tal fenômeno que, após a descrição de Camara Jr., foi revisto por Bisol $(2003,2010)$. Tais autores discutiram a assimetria do processo de alteamento, pois a vogal posterior /o/ demonstra-se mais sensível a ele, como é possível ver em palavras como pérola - frequentemente realizada como pér[u]la -, enquanto a vogal anterior /e/ apresenta mais resistência, como se verifica em palavras como almôndega e pálpebra - termos que, aparentemente, podem soar menos naturais com a vogal alta anterior, almônd[i]ga e pálp[i]bra, do que termos com a vogal posterior alta.

$\mathrm{Na}$ avaliação de Camara Jr., na verdade, o alteamento de /e/ nesse contexto era uma impossibilidade na fala culta carioca de seu tempo, enquanto Bisol defendeu que, atualmente, há uma instabilidade no PB e que a articulação anterior tende a se regularizar com a vogal alta, o que faria tal posição silábica, em etapas futuras do Português, teoricamente, ter um quadro vocálico semelhante à posição postônica final, com três vogais /i a u/. Considera-se aqui que na fala culta da década de 1940, que foi alvo da descrição de Camara Jr., provavelmente a variante [i] ainda era muito incomum entre os falantes escolarizados, não tendo sido percebida pelo ouvido certamente apurado do linguista. Assim, foi importante rever o comportamento atual dessa vogal, na fala culta ou não, visto que quase 80 anos se passaram desde sua descrição.

Esta pesquisa verificou o que Camara Jr. e Bisol defenderam, partindo da hipótese geral de que a mudança para o quadro de três vogais se encontra em fase 
final de implementação e os índices de alteamento teriam aumentado no período entre a descrição de Camara Jr. e a atualidade, tornando-se produtivo em quaisquer segmentos da comunidade de fala fluminense.

Destaca-se que o estudo do vocalismo postônico medial difere-se de outros contextos átonos porque as proparoxítonas têm diversas especificidades, o que se discute na seção 5. Para buscar esclarecer as questões que envolvem o tema, investigaram-se amostras sociolinguísticas dos anos 1970/80 e 2000, levantadas nas regiões metropolitanas do Rio de Janeiro e de Lisboa. Além disso, realizou-se uma análise pontual do léxico dessas amostras, em consideração aos já comentados aspectos peculiares dos termos proparoxítonos. O trabalho contou ainda com uma investigação bibliográfica diacrônica e uma análise de questionários e de um teste de leitura aplicados a falantes cariocas a fim de registrar uma quantidade maior de termos proparoxítonos. Por fim, realizou-se uma interpretação do vocalismo postônico não final, avaliando-se os resultados desta pesquisa e outros trabalhos teóricos e empíricos que abordaram o tema.

\section{O VOCALISMO POSTÔNICO MEDIAL EM PORTUGUÊS}

Trabalhos diacrônicos sobre o Português dizem que, desde o período medieval, as vogais médias sofrem alteamento na sílaba postônica final, onde as sete vogais tônicas /i $\varepsilon$ e a o $ว$ u/ se reduziram para três /i a u/. Sobre a sílaba postônica medial, alguns autores descreveram que as médias já podiam apresentar ligeiro fechamento (cér/ę/bro, árv/ơ/re) antes do século XVI. Após sua implantação no Brasil, a língua seguiu diferentes caminhos. No PE, o alteamento se implementou ao longo dos séculos em todo o vocalismo átono, em que surgiu também um novo segmento [i], de articulação central. Diferentemente, como é consabido, o PB apresenta até hoje variação em seu vocalismo átono, especialmente nas posições pretônica e postônica medial. Dessa forma, parte desta pesquisa se propôs a comparar as duas variedades na diacronia e na sincronia atual, permitindo, ao investigar o processo de alteamento, que já está totalmente concluído no PE, compreender melhor a variação que ainda há no PB.

A bibliografia da fonologia histórica referente ao período entre os séculos XVI e XIX apresenta poucas fontes que podem ajudar a delimitar historicamente quando o quadro vocálico postônico medial se tornou assimétrico no PB e quando se iniciou e se concluiu a implementação total do alteamento e da posteriorização de /e/ para [i] no PE.

Apesar de tais dificuldades, em Naro (1973), lê-se a hipótese de que a vogal /e/ teria sido alteada no PB somente no século XX (até 1938), em sílabas iniciais e finais, mas teria persistido nas sílabas mediais postônicas e pretônicas: venerador, númerro; enquanto no PE, o alteamento de /e/, nessas posições, já teria se concluído 
até o século XVIII, o que também defendem outros autores. Para Marquilhas (2003), existem indícios de que as variantes inovadoras $[\dot{i}, \mathrm{u}]$ e o apagamento já ocorriam em todos os contextos átonos desde o século XVII, generalizados por um processo de analogia, mas a redução geral do vocalismo átono Português só pode ser certamente reconhecida muito recentemente. As descrições de Gonçalves Viana $(1973$; 1982) e Barbosa (1988) dos séculos XIX e XX também indicam que o vocalismo átono do $\mathrm{PE}$, inclusive o postônico não final, se regularizou nas vogais $[\mathrm{i}, \mathrm{a}, \mathrm{u}]$ muito recentemente.

Como há poucos trabalhos atuais sobre este tema nas outras regiões do Brasil (cf. DE PAULA, 2015), ainda não é possível ter uma visão sociolinguística ampla do fenômeno no $\mathrm{PB}$, mas os dados dos trabalhos já realizados conseguem demonstrar que existe grande variação no país no âmbito desse quadro vocálico. Vários deles encontraram uma resistência maior da vogal anterior /e/ para sofrer alteamento, por diferentes motivos. A proposta mattosiana de que existem quatro segmentos /i E a U/ no vocalismo postônico não final ainda apresenta algum reflexo na atualidade. Por outro lado, a observação atenta dos fatores motivadores da manutenção de /e/ encontrados em tais trabalhos mostra que eles são geralmente fatores de ordem social ou lexical. As primeiras etapas desta pesquisa também demonstraram isso e, assim, a assimetria do contexto postônico medial foi considerada o reflexo de uma instabilidade fonológica - de acordo com Bisol (2003) - também observada em outros estágios do Português.

Paralelamente, a literatura contemporânea sobre o vocalismo átono do PE (MATEUS; ANDRADE, 2000; e outros) aponta que essa variedade, atualmente, apresenta regularidade fonética em todas as posições átonas. Quanto às vogais postônicas não finais, raramente citadas, nunca não registradas características próprias e elas só podem ser atestadas em exemplos que reúnem proparoxítonas e paroxítonas. De tudo isso, concluiu-se que o quadro vocálico não final do $\mathrm{PE}$ não pode ser tratado isoladamente das outras posições átonas. Ainda assim, não há uma amostra controlada que evidencie a redução das vogais átonas portuguesa e permita constatar as descrições realizadas. Também não há unanimidade quanto à interpretação da estrutura subjacente desta variedade do Português, pois o valor fonológico de [i] é de difícil observação e definição. Sobre tal questão fonológica, há trabalhos teóricos que observaram os aspectos do PE e serão discutidos no item 6 , em que se realiza uma comparação com o vocalismo do PB.

\section{ASPECTOS METODOLÓGICOS DA PESQUISA}

A análise sociolinguística realizada procurou atestar tendências de que os quadros átonos se estabilizem no Brasil, a exemplo de Portugal, ou de que a variação entre médias e altas, especialmente na posição postônica medial, possa persistir por muito tempo nessa variedade. 
Partiu-se da hipótese de que os aspectos assimétricos entre /e, o/ - que foram observados e discutidos por outros autores e também vistos nas primeiras etapas da pesquisa - deixarão de existir com o passar do tempo e mudança se estabelecerá a favor de /i u/. Para esclarecer essa hipótese, foram descritos e comparados dados das últimas quatro décadas de fala culta e popular do estado do Rio de Janeiro e da região metropolitana de Lisboa. Por conta da especificidade do tema e das dificuldades para encontrar em grande quantidade os termos proparoxítonos estudados, a análise foi complementada com dados de Atlas linguísticos (DE PAULA, 2008) e um questionário, para levantamento e observação mais ampla das vogais estudadas.

Os corpora sociolinguísticos do PB referentes às décadas de 1970 e 1980 contam com 121 entrevistas do tipo DID. Os de fala popular são do Atlas Etnolinguístico dos Pescadores do Estado do Rio de Janeiro (APERJ) e do Programa de Estudos sobre o Uso da Língua (PEUL 80), enquanto os dados de fala culta são referentes ao Corpus Norma Urbana Oral Culta do Rio de Janeiro (NURC- RJ). Da década de 2000, foram consideradas 45 entrevistas do tipo DID do Projeto Concordância RJ, de fala culta e popular, e do Corpus PEUL 2000, de fala popular.

Como dito, complementou-se a pesquisa com 17 gravações de um questionário (perguntas e identificação de figuras) e um teste de leitura realizados por cariocas de três níveis de escolaridade. Levantaram-se as palavras através de 32 perguntas como "Qual o nome da pessoa que fica no hotel por algum tempo?" [Hóspede]; 22 figuras de objetos ou situações como brócolis, tráfego; e trechos de leitura como "Nunca considerei a [hipótese] de colocar alguma [prótese] de silicone. Além de achar muito perigoso, o motivo é [frívolo]" que somam 23 itens.

Os corpora do PE dos anos 1970 estudados somam 17 entrevistas do tipo DID da única amostra dessa década, o Corpus Português Fundamental (outras 18 entrevistas do corpus não apresentaram as vogais desejadas). Tais gravações são de falantes cultos e não cultos de Lisboa e têm duração aproximada de apenas 04 minutos cada. O preenchimento das células sociais não é regular e muitas delas não são preenchidas. Referentes à década 2000, foram consideradas 36 entrevistas do Corpus Concordância, 18 da área metropolitana de Oeiras e 18 de Cacém.

Os dados sociolinguísticos do PB foram analisados no programa Goldvarb-X e também no ponto de vista lexical e no âmbito do idioleto, investigando-se possíveis condicionamentos idiossincráticos ou lexicais na realização das vogais médias, em especial de /e/.

As variáveis extralinguísticas controladas foram faixa etária; escolaridade; localização geográfica: região metropolitana, capital ou Norte do estado; e sexo. 
As variáveis linguísticas foram contexto antecedente; contexto subsequente; classe do vocábulo: substantivo, adjetivo, verbo; classificação lexical: termo técnico, usual, ou pouco usual; topônimo e antropônimo (DE PAULA, 2010); natureza da vogal da sílaba antecedente; natureza da vogal da sílaba subsequente; e posição da vogal na palavra (na raiz ou em outros morfemas).

\section{PANORAMA DOS RESULTADOS PARA O PORTUGUÊS}

Como foi prenunciado, a análise da fala fluminense visou averiguar porque o alteamento na posição postônica não final já está implementado em /o/, mas ainda encontra resistência em /e/; caracterizar a natureza dessa resistência, verificando as propostas de outros autores. Por conta de sua brevidade e seu objetivo, a apresentação de cada etapa realizada não se propõe a expor amplamente o desenvolvimento da análise, mas resumir com indicações pontuais os principais resultados encontrados na investigação que está detalhada em De Paula (2015).

\subsection{Fala espontânea fluminense}

As amostras sociolinguísticas das décadas de 1970/1980 e de 2000 somaram 166 entrevistas e 1844 ocorrências de vogal média postônica não final. O léxico apresentou 89 proparoxítonas: $43 \mathrm{com} / \mathrm{el}$ - alfândega, almôndega, amássemos, Aristóteles, câmeras, centímetro, célebre, cérebro, córrego, estudássemos, exógenos, fenômeno, fôlego, gênero, hidrômetro, hipótese, impeto, indígena, intérprete, inúmeros, Mariângela, milímetro, nádega, número, ópera, pálpebra, paralelepípedo, parâmetro, perímetro, pêssego, prótese, quilômetro, quiséssemos, tivéssemos, tráfego, úlcera, uníssemos, útero, velocípede, vértebras, véspera, víscera, vivêssemos; e $46 \mathrm{com} / \mathrm{o} /$ postônicos mediais - abóbora, Acrópole, Adrianópolis, agrícola, âncora, árvore, autônomo, biólogas, bússola, carnívoro, catálogo, catástrofe, cômoda, cômodo, cômoro, Débora, diálogo, época, Florianópolis, fósforo, gastrônomo, Heliópolis, herbivoro, ídolo, incômodo, indole, Mariópolis, mármore, método, metrópole, monótono, Nápoles, Nilópolis, pároco, Pentágono, pérola, Petrópolis, polígono, psicólogo, sambódromo, semáforo, símbolo, sociólogo, Távola, Teresópolis, tômbolos. As proparoxítonas com vogal /e/ totalizaram 485 ocorrências (26,3\% dos dados) e aquelas com vogal /o/, 1359 ocorrências.

Esse universo lexical é muito pequeno se comparado aos outros padrões acentuais do Português, tanto em variedade de lexemas como em frequência de ocorrência. Além disso, ele condiciona fortemente os resultados correspondentes às variáveis linguísticas controladas no trabalho, como o contexto fonético em que as vogais aparecem, por exemplo. Isso significa que a seleção de uma variável 
linguística como relevante pelo programa de análise estatística, por exemplo, a consoante em contexto subsequente, está geralmente relacionada com a frequência de alguns itens lexicais. É o caso das consoantes $/ \mathrm{m} / \mathrm{e} / \mathrm{t} /$ que remetem, quase sempre, ao radical -metro: milímetro, centímetro, quilômetro etc. Como consequência dessa dimensão lexical do fenômeno, todas as variáveis linguísticas acabaram sendo desconsideradas e, em contrapartida, De Paula $(2010,2015)$ realizou uma atenta análise lexical dos corpora, resumida na seção 5.

A primeira análise sociolinguística da pesquisa foi realizada na dissertação de De Paula (2010) e diz respeito apenas às décadas de 1970 e 1980. Os falantes do PEUL 80 , que não têm ensino superior, não mantiveram nem $1 \%$ das vogais médias /e/ e /o/, tendo sempre apagado ou reduzido ambas as vogais. Paralelamente, a performance dos pescadores do APERJ, também pouco escolarizados, foi quase categórica em realizar as vogais altas $(93,7 \%$ de alteamento da vogal /e/ e $95,5 \%$ de da vogal /o/, desconsiderando-se os muitos casos de apagamento). $\mathrm{Na}$ análise multivariada realizada na dissertação, o comportamento dos falantes deste corpus foi radicalmente diferente da fala culta carioca da mesma década: no APERJ, a aplicação da regra do alteamento teve peso relativo de 0.737 ; em contraste com o NURC, que, com $21,8 \%$ de alteamento de /e/, teve peso relativo de apenas 0.052 (DE PAULA, 2010, p. 102).

Apresentam-se, a seguir, na Tabela 1 , os resultados gerais do estudo da mudança em tempo real de curta duração nas falas culta e popular entre 1970/80 e 2000, realizado na tese de DE PAULA (2015). Nesta etapa diacrônica, foram considerados apenas os corpora NURC, PEUL e Concordância, referentes à região metropolitana do Rio de Janeiro, sem o corpus APERJ, que não tem equivalente geográfico na atualidade. Como explicitam esses percentuais diacrônicos gerais, ambas as vogais médias /e, o/ postônicas não finais estão em variação com as altas $/ \mathrm{i}, \mathrm{u} /$, nas duas sincronias, revelando-se também indícios de um processo avançado de mudança em direção à implementação do quadro vocálico /i, a, u/:

Tabela 1 Índices gerais da variação na fala fluminense - Décadas de 1970/1980 e 2000.

\begin{tabular}{|c|c|c|c|c|c|c|}
\hline \multicolumn{7}{|c|}{ CORPORA NURC 1970 E PEUL 80} \\
\hline \multirow[b]{2}{*}{ Vogal /e/ } & \multicolumn{2}{|c|}{ ALTEAMENTO } & \multicolumn{2}{|c|}{ MANUTENÇÃO } & \multicolumn{2}{|c|}{ APAGAMENTO } \\
\hline & $58 / 128$ & $45,3 \%$ & $68 / 128$ & $53,1 \%$ & $02 / 128$ & $1,6 \%$ \\
\hline Exemplo & \multicolumn{2}{|c|}{ ['ve $\int$ pire] } & \multicolumn{2}{|c|}{ ['vehtebire] } & \multicolumn{2}{|c|}{ ['ve $\left.\int \mathrm{p} r \mathrm{e}\right]$} \\
\hline Vogal /o/ & $243 / 311$ & $78,1 \%$ & $11 / 311$ & $3,6 \%$ & $57 / 311$ & $18,3 \%$ \\
\hline Exemplo & \multicolumn{2}{|c|}{ [aw'tõnumu] } & \multicolumn{2}{|c|}{ [a'boboir] } & \multicolumn{2}{|c|}{ [aw'tõmeS] } \\
\hline
\end{tabular}


Uma história de investigações sobre a Língua Portuguesa

\begin{tabular}{|c|c|c|c|c|c|c|}
\hline \multicolumn{7}{|c|}{ CORPORA CONCORDÂNCIA RJ E PEUL 2000} \\
\hline & \multicolumn{2}{|c|}{ ALTEAMENTO } & \multicolumn{2}{|c|}{ MANUTENÇÃO } & \multicolumn{2}{|c|}{ APAGAMENTO } \\
\hline Vogal /e/ & $40 / 79$ & $50,6 \%$ & $34 / 79$ & $43,1 \%$ & $05 / 79$ & $6,3 \%$ \\
\hline Exemplo & \multicolumn{2}{|c|}{ [fe'nõminu] } & \multicolumn{2}{|c|}{ [fe'nõmenu] } & \multicolumn{2}{|c|}{ ['nũs] } \\
\hline Vogal /o/ & $327 / 351$ & $93,2 \%$ & 06/351 & $1,7 \%$ & $18 / 351$ & $5,1 \%$ \\
\hline Exemplo & \multicolumn{2}{|c|}{ ['Epuke] } & \multicolumn{2}{|c|}{ ['E:poke::] } & \multicolumn{2}{|c|}{ ['вpe] } \\
\hline
\end{tabular}

A vogal posterior, em especial, quando não sofre cancelamento, é realizada alta na maioria absoluta dos dados de fala popular e culta, nas duas épocas estudadas $(78,1 \%$ e $93,2 \%$ de alteamento). Por outro lado, os dados de /e/ - a única vogal que apresentou variação passível de análise estatística -, expõem uma resistência significativa da articulação média no contexto anterior, o que ratifica parcialmente a visão de Camara Jr. (1970). Entretanto, fica evidente que tal resistência existe apenas no nível fonético, sobretudo na fala dos indivíduos mais escolarizados (ou que monitoram o seu discurso, segundo outras etapas da pesquisa), pois a vogal média /e/ convive com realizações como cér[i]bro, indig[i]na e vésp[i] ra, tanto na fala culta quanto na popular, que não causam estranhamento ou são estigmatizadas.

Paralelamente, a análise multivariada resumida a seguir (Tabela 2) refere-se à vogal anterior $/ \mathrm{e} /$, pois a posterior $/ \mathrm{o} /$, como esperado, foi quase categoricamente realizada $[\mathrm{u}]$ na fala espontânea. Além disso, foi excluído o PEUL 80, de fala popular carioca, em que o alteamento de /e/ e /o/ foi categórico. A fala escolarizada foi fator preponderante para a manutenção de /e/:

Tabela 2 Fator condicionador do alteamento da vogal média anterior postônica medial na fala da região metropolitana do Rio de Janeiro - Décadas de 1970/1980 e 2000 .

\begin{tabular}{|c|l|c|c|c|}
\hline \multirow{2}{*}{ VARIÁVEIS } & \multicolumn{1}{|c|}{ FATORES } & OCO & $\%$ & P. R. \\
\hline \multirow{3}{*}{ Escolaridade } & Fundamental & $\mathbf{3 5 / 3 7}$ & $\mathbf{9 4 , 6 \%}$ & $\mathbf{0 . 9 3 8}$ \\
\cline { 2 - 5 } & Médio & $23 / 34$ & $67,6 \%$ & 0.645 \\
\cline { 2 - 5 } & Superior & $40 / 129$ & $31,0 \%$ & 0.281 \\
\hline \multicolumn{2}{|c|}{ Signif: 0.000} & \multicolumn{3}{|c|}{ Input: 0.535} \\
\hline
\end{tabular}

Fonte: De Paula (2010: 102). 
Os pesos relativos deixam claro que o aumento gradual da escolaridade desfavorece o alteamento, sendo a principal razão para a restrição do processo. Camara Jr. sugeriu que o alteamento para [i] era inadmissível pelos cariocas (cultos) até 1970, mas os dados demonstram sua usualidade, havendo na comunidade variação [e] [i] na realização do fonema /e/ original.

Além desta análise, a escolaridade foi a única variável selecionada em todas as demais. Além disso, a observação dos falantes com até o Ensino Fundamental demonstrou que a mudança já está prevista no nível subjacente da fala popular, com um quadro simétrico /i a u/, e há quase categoricidade na realização das vogais como altas, à semelhança do contexto postônico final. Os percentuais de alteamento de /e/ entre os falantes que estudaram até o Ensino Fundamental II foram de 93,5\% (P. R. 0.737), como foi comentado, e de 85,7\% (P. R. 0.897), respectivamente nas décadas de 1970/1980 e 2000 (cf. DE PAULA, 2010, p. 102; 2015, p. 120).

Todos os dados demonstram a produtividade do alteamento e um estágio avançado da mudança para o quadro simétrico /i a u/. Ficou assim demonstrado que, na fala espontânea do Rio de Janeiro, a assimetria é resultado da resistência de /e/ entre os falantes mais escolarizados.

\subsection{Fala monitorada carioca}

Os dados sociolinguísticos foram comparados com os questionários e o teste de leitura aplicados a falantes cariocas. Eles totalizaram 1292 dados, entre 738 casos de vogal /e/ e 554 de /o/. Foram descartados 18 casos de cancelamento e abaixamento além de uma das entrevistas. Assim, consideram-se 17 gravações: 542 dados de perguntas, 359 de figuras e 391 de leitura.

Os resultados encontrados são coerentes com a hipótese, advinda da análise de Atlas Linguísticos por De Paula (2008; 2010), de que a fala monitorada em questionários inibe o alteamento em postônicas mediais. Porém, chegaram ainda a surpreender índices muito elevados de conservação das vogais médias, inclusive de /o/, o que contribuiu em muito para a discussão sobre a constituição fonológica deste contexto vocálico. Os cariocas produziram muito mais a articulação média de ambas as vogais em comparação com os corpora sociolinguísticos. Por outro lado, embora a assimetria tenha sido bem menor que na fala espontânea, a vogal anterior /e/ ainda foi menos sensível ao alteamento que /o/, em consonância com as outras etapas da pesquisa. Veja-se os percentuais gerais para /e/ na Tabela 3 a seguir: 
Tabela 3 Índices da realização da vogal média anterior postônica medial em dados de Questionários e Leitura.

\begin{tabular}{|c|c|c|c|c|}
\hline \multicolumn{5}{|c|}{ QUESTIONÁRIOS E LEITURA - VOGAL /E/ } \\
\hline ESTRATÉGIA & \multicolumn{2}{|c|}{ ALTEAMENTO } & \multicolumn{2}{|c|}{ MANUTENÇÃO } \\
\hline Perguntas & $141 / 279$ & $50,5 \%$ & $138 / 279$ & $49,5 \%$ \\
\hline Exemplo & \multicolumn{2}{|c|}{ ['aspiru] } & \multicolumn{2}{|c|}{ ['a]peru] } \\
\hline Figuras & $92 / 202$ & $45,5 \%$ & $110 / 202$ & $54,5 \%$ \\
\hline Exemplo & \multicolumn{2}{|c|}{ [tefi'mõmitru] } & \multicolumn{2}{|c|}{ [tef'mõmetru] } \\
\hline Leitura & $98 / 257$ & $38,1 \%$ & $159 / 257$ & $61,9 \%$ \\
\hline Exemplo & \multicolumn{2}{|c|}{ ['kahsiri] } & \multicolumn{2}{|c|}{ ['kahseri] } \\
\hline Total & 331 & $44,9 \%$ & 407 & $55,1 \%$ \\
\hline
\end{tabular}

Os dados foram analisados em separado de acordo com a estratégia de investigação, considerando que foram produzidos em diferentes estilos de fala. Os resultados demonstram que os falantes, em geral, diminuem gradualmente a produção do alteamento em /e/ conforme aumenta a formalidade do inquérito: 50,5\% $>45,5 \%>38,1 \%$. Enquanto os percentuais das estratégias de perguntas e figuras permaneceram na neutralidade, na leitura, presumivelmente, as realizações foram muito mais conservadoras, ultrapassando $60 \%$ de manutenção da média /e/. No total geral, a articulação média sobrepõe levemente o alteamento, em 55,1\% dos casos.

Como dito, embora também tenha sido inibido na vogal /o/, o alteamento foi muito mais produtivo nesse contexto: foi realizado em $64,8 \%$ dos casos totais, mas surpreendentemente chegou a ser preterido na leitura, com apenas $44,8 \%$ de [u] (DE PAULA, 2010, p. 128). É fundamental observar que tal percentual é bastante equilibrado com a realização da vogal /e/ nos dados de leitura $-38,1 \%$ de alteamento -, isenta de qualquer assimetria.

As variáveis relevantes nas análises multivariadas foram observadas em percentuais na fala monitorada e entre elas apenas a escolaridade destacou-se na variação das vogais (p. 128-135), como se esperava. Por outro lado, os falantes não atentaram ao caráter usual ou técnico das proparoxítonas e, na leitura, houve perceptível receio de todos ao se depararem com esse acento, mesmo em palavras comuns na fala carioca, como véspera e prótese. Os falantes com nível fundamental foram extremamente cautelosos ao ler, atingindo $70 \%$ de manutenção de /e/. 
Assim, a categoricidade do fenômeno no contexto posterior - verificada em todas as amostras sociolinguísticas de 2000 - e no contexto anterior - verificada entre os falantes de nível fundamental - não se mantém nos discursos mais formais, quando todos os falantes recuperam, de forma consistente, as vogais conservadoras. A manutenção de /o/, ainda que em menor número que de /e/, é significativa porque o alteamento desta vogal já está estabelecido na fala espontânea fluminense, culta e popular, desde a década de 1940, conforme atestou Mattoso Camara. Em suma, conforme o monitoramento do discurso aumenta, o alteamento é refreado, mais intensamente na vogal /e/, mas também de forma expressiva na vogal /o/.

\subsection{Fala espontânea lisboeta}

As 53 entrevistas do PE falado na região metropolitana de Lisboa totalizaram 140 ocorrências de vogal média postônica não final - 30 dados de 1970 e 110 dados de 2000:

Tabela 4 Índices da variação de $\left\langle e>\right.$ e $\langle 0\rangle^{2}$ postônicos mediais na região de Lisboa Décadas de 1970 e 2000.

\begin{tabular}{|c|c|c|c|c|c|c|}
\hline \multicolumn{7}{|c|}{ CORPUS PORTUGUÊS FUNDAMENTAL LISBOA 1970} \\
\hline \multirow[b]{2}{*}{ Vogal <e > } & \multicolumn{2}{|c|}{ ALTA } & \multicolumn{2}{|c|}{ MÉDIA } & \multicolumn{2}{|c|}{ APAGAMENTO } \\
\hline & $15 / 24$ & $62,5 \%$ & $0 / 24$ & $0 \%$ & $09 / 24$ & $37,5 \%$ \\
\hline Exemplo & \multicolumn{2}{|c|}{ [fí'nominu] } & & & \multicolumn{2}{|c|}{ [i'pots] } \\
\hline Vogal $<0>$ & 04/06 & $66,7 \%$ & $0 / 06$ & $0 \%$ & $02 / 06$ & $33,3 \%$ \\
\hline Exemplo & \multicolumn{2}{|c|}{ ['metudu] } & & & \multicolumn{2}{|c|}{ [ka'tal] } \\
\hline \multicolumn{7}{|c|}{ CORPUS CONCORDÂNCIA LISBOA 2000} \\
\hline & \multicolumn{2}{|c|}{ ALTA } & \multicolumn{2}{|c|}{ MÉDIA } & \multicolumn{2}{|c|}{ APAGAMENTO } \\
\hline Vogal <e> & $32 / 79$ & $40,5 \%$ & $0 / 79$ & $0 \%$ & $47 / 79$ & 59,5 \\
\hline Exemplo & \multicolumn{2}{|c|}{ ['nũmiru] } & & & \multicolumn{2}{|c|}{$\left[{ }^{\prime} n \tilde{u}^{\mathrm{m}} \mathrm{r} U\right]$} \\
\hline Vogal $\langle 0\rangle$ & $16 / 31$ & $51,6 \%$ & $0 / 31$ & $0 \%$ & $15 / 31$ & $48,4 \%$ \\
\hline Exemplo & \multicolumn{2}{|c|}{ ['idulvS] } & & & \multicolumn{2}{|c|}{ [si'mafru] } \\
\hline
\end{tabular}

2 São usados aqui grafemas, pois a descrição nesta seção não pretende discutir o valor fonológico dessas vogais. 
Os poucos dados levantados não permitiram a observação precisa dos fatores sociais, mas eles evidenciam a categoricidade das vogais altas em Lisboa já em 1970. Em variação apenas com o apagamento, houve 15 realizações de vogal <e> nas variantes [i], [I] ou ['], que são $62,5 \%$ dos dados. A vogal $<0>$ foi alteada para [u] ou [ $\left.{ }^{\cup}\right]$ em 04 casos, $66,7 \%$ do total de 06 .

$\mathrm{Na}$ década de 2000, os 36 falantes de Oeiras e Cacém ou reduziram <e > e $<0>$ para a articulação alta ou as apagaram em percentuais expressivos, assim como os lisboetas de 1970. O cancelamento foi ainda mais produtivo, evidenciando seu aumento nas últimas décadas.

Os dados destes informantes indicam haver simetria entre as vogais $<\mathrm{e}>\mathrm{e}$ $<0\rangle$, tendo sido as taxas de alteamento e apagamento de cada vogal muito semelhantes. Com forte tendência a reduções, as vogais realizaram-se extremamente débeis ou foram apagadas.

Sobre as variáveis sociais, pôde-se observar apenas que, nos anos 1970, o cancelamento se concentrou na fala menos escolarizada, mas a raridade dos dados não permitiu maiores conjecturas. Obviamente, os resultados aqui apresentados não podem ser generalizados para a variedade do PE como um todo, mas corroboram as descrições fonéticas do PE já realizadas.

\section{ANÁLISE LEXICAL E IDIOSSINCRÁTICA}

Em geral, os trabalhos que envolvem os vocábulos proparoxítonos consideram o caráter marcado desse padrão acentual no Português, por ser o seu acento menos produtivo, muitas vezes ponderando que talvez ele não seja natural na língua porque se perdeu no latim vulgar e teve uma reentrada tardia, através de empréstimos eruditos do latim clássico e do grego. As proparoxítonas também são semanticamente peculiares, já que constituem, em sua maioria, termos técnicos e pouco usuais. Apenas algumas delas ganharam espaço no cotidiano dos falantes do Português porque, com o passar do tempo, seus conceitos se popularizaram. Nos dados deste trabalho, são exemplos árvore, número, centímetro, psicólogo etc.

Com base na contagem dos verbetes do Dicionário Houaiss (HOUAISS; VILLAR, 2001) de Araújo et al. (2007), De Paula (2010, p. 47-55) avaliou, de acordo com a usualidade, as 3.631 proparoxítonas dicionarizadas do Português que apresentam /e/ e /o/ postônicos não finais. A autora classificou 53 proparoxítonas como termos usuais: pêssego, época; 134 como termos pouco usuais: efêmero, déspota; 294 como termos reconheciveis e/ou técnicos: calorímetro, museólogo; e 3.150 como termos em desuso, restritos e/ou técnicos não reconheciveis: cecidógeno, monáxono. Essa classificação pôde ser ratificada com a frequência lexical nas entrevistas do corpus NURC-RJ levantada por Marques (1996). 
Os termos usuais, que se retomam a seguir, são os únicos que fazem parte do vocabulário ativo de todos os falantes, ou seja, do conjunto de vocábulos que são adquiridos no convívio familiar e ocorrem com alta frequência na fala (DE PAULA, 2010:49): com vogal /e/: almôndega, áspero, bafômetro, câmera, centímetro, cérebro, cócega, cólera, córrego, fôlego, frutífero, gênero, hóspede, mamífero, milímetro, número, pêssego, quilômetro, sonífero, termômetro, tíquete, tráfego, úlcera, útero, velocímetro, velocípede, véspera; e com vogal /o/: abóbora, agrícola, âncora, apóstolo, árvore, autônomo, brócolis, bússola, catálogo, cócoras, cômoda, cômodo, diálogo, época, fósforo, horóscopo, idolo, incômodo, mármore, monótono, pérola, própolis, psicólogo, sambódromo, semáforo, símbolo. Os demais itens geralmente são aprendidos em situações formais que passam pelo texto escrito ou pelo convívio escolar.

Os corpora desta pesquisa apresentam diversas restrições lexicais a serem consideradas, como a concentração de todas as ocorrências de milímetro, centímetro, âncora e bússola na fala dos pescadores ou a presença do topônimo Nilópolis apenas entre os falantes de Nova Iguaçu. Muitas vezes, a frequência de uma proparoxítona é influenciada pelo cotidiano do falante, a região em que vive, a profissão que exerce etc. Na fala culta, houve $20 \%$ de proparoxítonas não usuais ou técnicas, enquanto na fala popular houve de $1,4 \%$ a $6 \%$. Além de tudo, nos resultados encontrados, os fatores lexicais, sociais e discursivos ofuscaram quaisquer condicionamentos fonéticos, os quais não puderam ser esclarecidos, como no caso de -metro, citado na seção 4.

Foram essas as razões que levaram a observar o fenômeno em questão sob a perspectiva teórica da Fonologia de Uso e da Teoria dos Exemplares. Nas palavras de Bybee, a Fonologia de Uso propõe "um modelo em que a variação e a mudança não são externas ao léxico e à gramática, mas inerentes a eles" (2002:287). Paralelamente, Cristófaro-Silva (2005) diz, segundo a Teoria dos Exemplares, que "efeitos de frequência expressam a organização probabilística do conhecimento linguístico" (p. 227). Considerou-se a possibilidade de que os poucos itens mais frequentes na fala espontânea encabeçassem a disseminação da variante inovadora, a vogal alta, sendo um modelo de mudança para os termos menos frequentes. Entretanto, a mudança investigada encontra-se em etapas finais de implementação, quando atestar suas motivações, seja na perspectiva variacionista ou funcionalista, é muito difícil. Também na proposta de Marquilhas (2003) para o PE, o alteamento nas postônicas não finais teria sido promovido pelos outros contextos átonos da língua, mais frequentes, mas nem mesmo sua hipótese pôde ser confirmada, pela raridade dos dados de outras sincronias. Esse caso ratifica o postulado laboviano de que se torna cada vez mais difícil ver os padrões de uma mudança em suas fases finais, pois é quando o processo se torna geral e perde suas restrições. 
Porquanto a regularização do vocalismo postônico não final em /i, a u/ tenha se mostrado, nesta pesquisa, ainda ser refreada somente por atuação de restrições sociais (nível de escolaridade) e discursivas (monitoramento do discurso), empreendeu-se uma apreciação pontual do léxico levantado nas entrevistas sociolinguísticas e do comportamento individual dos falantes. Como se esperava, a frequência dos termos proparoxítonos na fala fluminense e também a produtividade de uma variante ou de outra é marcada no nível individual. O vocábulo córrego, por exemplo, que teve 07 realizações, foi produzido por apenas um informante, todas as vezes com cancelamento da vogal: ['kohigu].

Idiossincrasias podem se afastar do comportamento geral de um grupo e, por isso, casos particulares como o citado têm sido relevantes na preservação residual de variantes médias na fala popular e na implementação do processo de alteamento entre os falantes cultos. Por exemplo, entre os informantes com Ensino Médio dos anos 2000, encontraram-se apenas 11 casos de manutenção da vogal média /e/. Percentualmente, esse grupo apresentou um comportamento mais próximo dos falantes com nível Superior da mesma sincronia do que daqueles só com Ensino Fundamental. De fato, eles variam a realização dessa vogal, enquanto os falantes menos escolarizados são regulares na implementação da alta anterior. Por outro lado, viu-se que os casos são concentrados. 05 dos 11 dados de /e/, ou seja, quase $50 \%$ deles, ocorreram na mesma entrevista, na qual o falante foi categórico em manter sempre [e] nos 05 vocábulos proferidos por ele: 02 dados de hidrôm[e]tro e 03 de núm[e]ro.

Dessa forma, a variação observou-se no grupo em geral, mas quase nunca no indivíduo. Como lembram Weinreich; Labov; Herzog, para Hermann Paul (1880, apud WEINREICH; LABOV; HERZOG, 2006), a consideração do idioleto é a única maneira de chegar à gramática e que "uma comparação das línguas individuais (...) produz uma certa 'média', que determina o que é realmente normal na língua” (p. 41) - questão que será retomada na seção a seguir.

\section{INTERPRETAÇÃO DO VOCALISMO POSTÔNICO MEDIAL EM PORTUGUÊS}

Apresenta-se aqui, por fim, a interpretação teórica do vocalismo postônico medial em Português decorrente dos resultados desta pesquisa e sua comparação com a literatura sobre o vocalismo do PB e do PE. Propostas sobre a constituição fonológica do PE interessarão também à interpretação do $\mathrm{PB}$ como uma gramática semelhante ou não ao PE nesse aspecto.

\subsection{Sobre o Português brasileiro}

A respeito do PB, Bisol (2003) apoia-se na Teoria Autossegmental e na Geometria de Traços e, com base em Clements (1991, apud Bisol, 2003:276), propõe 
que o vocalismo do Português constitui um modelo estruturado em camadas hierárquicas, cada uma representando um traço de abertura ([aberto 1], [aberto 2], [aberto 3]). Segundo Clements, nas línguas românicas há um registro de 03 vogais, um registro de 05 e um registro de 07 , sendo os menores resultantes da anulação dos traços [aberto 3] e/ou [aberto 2]. Bisol entende que a neutralização se implementa gradualmente no PB e que na sílaba postônica não final há instabilidade entre os registros de 05 e de 03 vogais, mas defende uma tendência de regularização em 3 vogais.

Com base nas análises sociolinguística e lexical desta pesquisa, defende-se aqui que a neutralização dos dois graus de abertura, 3 e 2, já se consolidou no PB também nas vogais postônicas não finais, que configurou na atualidade um quadro de 03 fonemas semelhante ao átono final, /i a u/. Vários aspectos dos corpora demonstram que a presença das vogais médias entre os falantes fluminenses é um caso de variação fonética, à semelhança do contexto átono final, e não de oposição, como ocorre no contexto pretônico. Não foram observados na literatura indícios que contrariem esta configuração fonológica em outras regiões do país, tão-somente constata-se uma rica variação regional, como é próprio do $\mathrm{PB}$ em muitos fenômenos variáveis.

O principal fato que respalda esta interpretação é a categoricidade do alteamento de /e/ e de /o/ na fala popular espontânea fluminense. Ao mesmo tempo, assim como nas outras regiões brasileiras, é igualmente possível verificar variação no estado do Rio de Janeiro. Os dados gerais dos anos 2000 indicam que as variantes [e] e [i] estão em equilíbrio entre os falantes de nível médio e superior de instrução. Além disso, comportamentos idiossincráticos indicam que a mudança para [i] se evidencia, mesmo na fala culta, ao mesmo tempo em que, na fala de alguns indivíduos, se verifica a resistência da variante conservadora [e]. Ou seja, vê-se no Rio de Janeiro um claro caso de variação entre duas formas de realizar o mesmo fonema.

Weinreich; Labov; Herzog (2006) entendem que o uso linguístico muda com a soma de "uma série de (...) mudanças de idioletos que se movem numa mesma direção” (p. 43). Tal visão é bastante evidente para o fenômeno estudado, pois no idioleto de muitos falantes fluminenses a mudança para /i/ se evidencia, mesmo na fala culta, assim como a variante conservadora pode ser marca individual de poucos falantes não cultos. Apesar do recorte metodológico que divide informantes cultos e não cultos, no nível individual, vê-se que a maioria dos falantes que compõem a comunidade de fala fluminense já implementa a redução da vogal.

\subsection{Sobre a distinção entre o Português brasileiro e o Português europeu}

Como foi dito, na literatura sobre o PE, em geral, há consenso quanto ao seu vocalismo átono ser regular em qualquer posição, mas é difícil determinar o esta- 
tuto fonológico de [i] e sua função distintiva em relação às demais vogais, o que é objeto de discussões. Para Mateus (1990), [i] é um alofone contextual de /e, ع/ nas sílabas átonas, mas, segundo interpretação de Veloso (2005; 2007; e outros), ele já possui o status de um fonema próprio dessas posições.

A respeito das distinções entre o $\mathrm{PB}$ e o $\mathrm{PE}$, Mateus resume a discussão defendendo a existência de um nível subjacente comum a todas as variedades da Língua Portuguesa e diferentes blocos de regras, que as distinguem no nível superficial, ou seja, na realização fonética. Para Mateus, ele manifesta-se completo na sílaba tônica e varia foneticamente a depender da posição átona. Assim, [i] seria apenas uma variante específica do PE. Veloso, com base na Fonologia de Elementos, prevê contextos morfológicos em que [i] estaria integrado à estrutura subjacente do $\mathrm{PE}$, demonstrando então o estabelecimento de uma mudança fonológica.

Veloso concorda com Mateus ao afirmar que são inquestionáveis pares de palavras de mesmo radical com um fonema /e/ ou / $/$ / tônico o qual se concretiza de forma diversa nas posições átonas. Ele exemplifica com $c / \varepsilon / g o, c[\mathrm{i}]$ gueira; $m / \mathrm{e} /$ do, $m[\mathrm{i}] d r o s o ;$ am/e/mos, am/e/is, am [i] am $[\mathrm{i}] s ;$ mas, para o autor, muitos termos que não têm essa equivalência morfofonológica nunca permitem associar [i] a um fonema tônico, sendo casos sem respaldo na hipótese de Mateus. São os monossílabos átonos, como que, de, te, se, lhe, e os nomes com tema em [i] átono, como nom [i]. Ele propõe, elencando diversos argumentos (2007:59), a existência de um /i / fonológico nesses casos, o qual corresponderia invariavelmente a uma realização [i] no PE. Para Veloso, “a aceitação desse item do inventário fonológico teórico do PEC (Português europeu continental) forneceria uma maior adequação explicativa às descrições fonológicas do Português no tocante à representação lexical das palavras em apreço" (2005:628). O segmento /ít seria, de acordo com esse ponto de vista, um elemento separador entre as variedades brasileira e europeia do Português. Assim, o PB, mais conservador, sofreria um alteamento gradual das vogais médias e baixas que ainda não é regular na maioria dos contextos átonos; o PE, mais inovador, seria regular na redução das vogais médias para altas em todas as sílabas átonas e receptivo a um novo segmento de articulação central no seu inventário fonológico.

Por existirem poucos trabalhos sobre as vogais do PE, esta pesquisa não pode concluir a respeito dos fonemas dessa variedade. Se [i] chegar a ter um valor fonológico atestado, haverá evidência suficiente de que os sistemas fonológicos do PE e do PB estarão apartados.

\section{CONCLUSÕES GERAIS SOBRE O VOCALISMO POSTÔNICO DO PORTUGUÊS}

Ainda que não seja possível definir o estatuto fonológico das vogais átonas do PE, a revisão da bibliografia sincrônica e diacrônica e a análise de dados bra- 
sileiros e portugueses das últimas décadas realizadas nesta pesquisa permitem concluir que as duas variedades são distintas, pelo menos no nível fonético, no âmbito das sílabas átonas, como se resume a seguir:

Em Portugal, são indiscutíveis (i) a implementação do alteamento, tanto de /e/ quanto de /o/; (ii) a simultânea posteriorização de /e/; e (iii) a produtividade do apagamento vocálico. Em suma, essa variedade apresenta regularidade na redução das vogais médias e é receptiva a um novo alofone, e possível fonema, [i]. No Brasil, o processo de alteamento das vogais médias postônicas /e/ e /o/ está em fases finais de implementação, mas o sistema ainda prevê variação fonética, o apagamento e a articulação média dessas vogais, o que já ocorria no Português quinhentista, embora atualmente apresente configurações sociais diferentes.

No contexto postônico não final, investigado nesta pesquisa, foram constatados fatores condicionadores para a variação, como a escolaridade, o monitoramento do discurso e alguns comportamentos idiossincráticos, mas a assimetria fonológica entre /e/ e /o/ não se verifica mais nos corpora fluminenses como foi notada na metade do século XX por Camara Jr. Ao mesmo tempo, constata-se na literatura que a variação entre vogais médias e altas postônicas não finais é legitima em todos os registros da fala brasileira já analisados, não havendo nenhuma análise que tenha observado a manutenção categórica das médias, seja de /e/ ou de $/ \mathrm{o} /$.

Por tudo isso, esta pesquisa pôde confirmar que as oposições entre vogais médias e altas postônicas não finais estão neutralizadas na variedade brasileira, à semelhança do vocalismo postônico final. Com o passar do tempo e os diferentes processos fonético-fonológicos sendo incorporados às gramáticas do $\mathrm{PB}$ e do $\mathrm{PE}$ (ainda que alguns possam ser refreados, como prevê a teoria da Variação e Mudança), as mudanças no vocalismo átono tendem a afastar, cada vez mais, essas duas variedades do Português.

\section{REFERÊNCIAS BIBLIOGRÁFICAS}

ARAÚJO, Gabriel; VIARO, Mário; GUIMARÃES-FILHO, Zwinglio; OLIVEIRA, Leonardo. As proparoxítonas e o sistema acentual do Português. In: ARAÚJO, Gabriel Antunes de (org.). O acento em Português: abordagens fonológicas. São Paulo: Parábola, 2007, p. 37-60.

BARBOSA, Jerónimo. Grammatica philosophica da Lingua Portuguesa ou princípios de grammatica geral aplicados à nossa lingoagem. Lisboa, 1822. Disponível em http:// bibdig.biblioteca.unesp.br/handle/10/6903.

BISOL, Leda. A simetria no sistema vocálico do Português brasileiro. Linguística - Revista de Estudos Linguísticos da Universidade do Porto. v. 5, p. 41-52, 2010. 
. A neutralização das átonas. Revista D.E.L.T.A, 19 (2), p. 267-276, 2003.

BRANDÃO, Silvia Figueiredo; SANTOS, Alessandra de Paula. O comportamento das vogais médias postônicas não finais na fala fluminense. In: HORA, Dermeval da (org.). Vogais: no ponto mais oriental das Américas. João Pessoa: Ideia, 2009, p. 101-110.

BYBEE, Joan. Word frequency and context of use in the lexical diffusion of phonetically conditioned sound change. Language Variation and Change, 14. Cambridge: Cambridge University Press, p. 261-290, 2002.

CAMARA Jr., Joaquim Mattoso. Para o estudo da fonêmica portuguesa. Rio de Janeiro: Padrão, 1977[1953].

. Estrutura da Lingua Portuguesa. Petrópolis: Vozes, 1970.

CRISTÓFARO-SILVA, Thaïs. Fonologia probabilística: estudos de caso do Português brasileiro. Lingua(gem). Macapá, v. 2, n. 2, p. 223-248, 2005.

DE PAULA, Alessandra. Variação e mudança no vocalismo postônico medial em Português. 2015. Tese (Doutorado em Língua Portuguesa) - Faculdade de Letras, Universidade Federal do Rio de Janeiro, Rio de Janeiro, 2015.

- Vogais médias postônicas não finais no Rio de Janeiro: produtividade lexical e processo de alteamento. In: MAGALHÃES, José Sueli (org.). Fonologia - Linguística in Focus 10. Uberlândia: EDUFU, 2014, p. 205-228.

. Vogais médias postônicas não finais na fala do estado do Rio de Janeiro. 2010. Dissertação (Mestrado em Língua Portuguesa). Faculdade de Letras, Universidade Federal do Rio de Janeiro, Rio de Janeiro, 2010.

- As vogais médias postônicas não finais em corpora de perfis sócio e geolinguísticos. Revista Estudos Linguísticos, v. 38 (1). São Paulo, p. 35-46, 2008. CD-ROM.

; BRANDAO, Silvia Figueiredo. Vogais em contexto postônico não final em variedades do Português: questões teóricas. Revista da ABRALIN, v. 14, p. 45-82, 2015.

; BRANDÃO, Silvia Figueiredo. F. Assimetria do quadro vocálico em contexto postônico não final: aspectos diacrônicos e realidades sincrônicas. Signum: Estudos de Linguagem, v. 15. Londrina: Editora UEL, p. 129-149, 2012.

HOUAISS, Antônio; VILLAR, Mauro. Dicionário Houaiss da Língua Portuguesa. São Paulo: Objetiva, 2001.

LABOV, William. Principles of linguistic change. Vol. 1. Oxford: Blackwell Publishers, 1994.

Sociolinguistic patterns. Philadelphia: University of Pennsylvania, 1972.

MARQUES, Maria Helena Duarte. O vocabulário da fala carioca. v. I, II e VIII. Rio de Janeiro: Faculdade de Letras/UFRJ, 1996.

MARQUILHAS, Rita. A Língua Portuguesa no século XVIII: cronologia de fenómenos fonológicos e sintácticos que caracterizavam o Português Europeu da época. Congresso 'O Século das Luzes'. Berlim, Humboldt Universidade de Berlim, 2003. Digital. 
MATEUS, Mira; Fonética, Fonologia e Morfologia do Português. Lisboa: Univ. Aberta, 1990. 2000.

. ANDRADE, Ernesto. The phonology of portuguese. Oxford: University Press,

NARO, Anthony. História do $e$ do o em Português: um estudo de deriva linguística. In: . Estudos diacrônicos. Petrópolis: Vozes, 1973, p. 9-51.

VELOSO, João. Schwa in European Portuguese: The phonological status of [i]]. In: CROUZET, Olivier; ANGOUJARD, Jean-Pierre (eds.). Actes des/Proceedings of JEL'2007. Schwa(s). 5. èmes Journées d'Etudes Linguistiques. Nantes: Université de Nantes, 2007, p. 55-60.

. Considerações sobre o estatuto fonológico de [i] em Português. Revista da Faculdade de Letras da Universidade do Porto. Linguas e Literaturas. XXII, p. 621-632, 2005.

VIANA, Gonçalves. Estudos de fonética portuguesa. Lisboa: Imprensa Nacional, 1973.

. Exposição da pronúncia normal portuguesa para uso de nacionais e estrangeiros. Lisboa: Imprensa Nacional, 1892.

WEINREICH, Uriel; LABOV, William; HERZOG, Marvin. Fundamentos empíricos para uma teoria da mudança linguística. Trad. Marcos Bagno. São Paulo: Parábola, 2006 [1968]. 
